\title{
What are the costs, capacity, and clinical implications of 'waiting for documented progression' in young West of Scotland patients prior to collagen cross linking?
}

\author{
Alasdair Simpson ${ }^{1} \cdot$ Kerr Brogan ${ }^{1} \cdot$ Kanna Ramaesh ${ }^{1} \cdot$ David Lockington $(1)^{1}$ \\ Received: 5 December 2020 / Revised: 10 December 2020 / Accepted: 27 January 2021 / Published online: 24 February 2021 \\ (c) The Author(s), under exclusive licence to The Royal College of Ophthalmologists 2021
}

Collagen crosslinking (CXL) has emerged as the standard intervention to arrest progression of corneal ectasia [1-5]. Since 2015, young patients with keratoconus in NHS Greater Glasgow and Clyde (NHSGGC), Scotland, have been monitored every 4-6 months in a dedicated optometrist-led early keratoconus clinic. Those with documented evidence of progression are offered CXL, a costeffective procedure intended to stabilise the cornea and avoid future corneal transplantation [6, 7]. CXL has been shown to be effective in arresting the progression of corneal ectasia in this younger age group at 2 and 5 years follow up $[1,8-10]$. Progression of keratoconus is known to be more aggressive in the younger age group, so CXL services were protected and prioritised in many corneal units during the COVID-19 pandemic [11]. These measures were necessary as rapid topographic changes may occur and result in corneal thinning progressing beyond standard treatment protocols (corneal thickness $<400 \mu \mathrm{m}$ ). [12] In light of this, the advocacy for early intervention with CXL at presentation rather than 'wait for documented progression' is growing for the younger age group. We wished to identify our younger patients with keratoconus and model the real-world clinical, financial costs, and service capacity implications of 'waiting for documented progression' prior to CXL.

\section{Methods}

Electronic records of patients $<21$ years of age at referral attending our early keratoconus clinic in NHSGGC between

David Lockington

davidlockington@hotmail.com

1 Tennent Institute of Ophthalmology, Gartnavel General Hospital, Glasgow, United Kingdom
January 2015 and September 2019 with a minimum of 1 year follow up were retrospectively reviewed. Demographic, topography, visual acuity, clinic attendance, and intervention data were analysed.

\section{Results}

We identified 76 patients (56 males and 20 females) with 142 eyes which had not previously undergone CXL. Mean age was 18 years (median 18, SD 1.91, range 14-21). Six patients had advanced disease with corneas considered too thin for conventional CXL at presentation (thinnest pachymetry $<400 \mu \mathrm{m})$. Sixty $(41 \%)$ eyes of 46 patients demonstrated documented progression. One patient's cornea progressed during monitoring intervals such that $\mathrm{CCT}$ was too thin for conventional CXL. Three patients declined treatment, leaving 56 eyes (39\%) of 42 patients proceeding to epithelium-off, accelerated, pulsed CXL. Twenty-nine right eyes and 27 left eyes were treated. Fourteen patients had each eye treated sequentially. There was no statistical difference in the mean age of patients with progression leading to CXL compared to those that did not receive CXL in the study period (17.8 vs 18.2 years, $p=0.48$ ). Those that went on to require CXL had significantly more extreme topographic measurements at first presentation compared to those who simply required monitoring (mean CCT 470.71 um vs 500.00 um $(p<0.01)$ and mean Kmax $57.64 \mathrm{D}$ vs 52.06D $(p<0.01))$.

The median time interval from initial presentation to CXL treatment was 40 weeks (mean 57; SD 48, range 3-214). In this time period, there was evidence of significant visual loss $(p=0.03)$ and topographic progression $(p<0.01)$ [See Table 1]. Mean length of time from listing to receiving CXL was 93 days (median 77.5, range 13-386). These 42 patients (56 eyes) attended an overall total of 196 clinic appointments prior to first eye CXL treatment 
Table 1 Presenting Pentacam topographic characteristics and visual acuity of 56 young eyes with keratoconus that underwent CXL following documentation of progression, with initial presentation, prior and post CXL treatment measurements.

\begin{tabular}{|c|c|c|c|c|c|}
\hline & Presentation $( \pm \mathrm{SD})$ & Prior to $\mathrm{CXL}( \pm \mathrm{SD})$ & $P$ value & Post CXL $( \pm$ SD) & $P$ value \\
\hline Mean Cyl (D) & $2.80 \pm 1.85$ & $3.84 \pm 2.04$ & $<0.1^{\mathrm{a}}$ & $3.60 \pm 2.19$ & $0.19^{\mathrm{a}}$ \\
\hline Mean spherical equivalent (D) & $-0.53 \pm 1.76$ & $0.18 \pm 1.82$ & $0.32^{\mathrm{a}}$ & $-0.09 \pm 1.96$ & $0.39^{\mathrm{a}}$ \\
\hline Mean Anterior K2 (D) & $49.01 \pm 4.04$ & $50.17 \pm 4.60$ & $<0.01^{\mathrm{a}}$ & $51.57 \pm 5.15$ & $<0.01^{\mathrm{a}}$ \\
\hline Mean Posterior K2 (D) & $-7.41 \pm 0.77$ & $-7.53 \pm 0.80$ & $<0.01^{\mathrm{a}}$ & $-7.75 \pm 0.88$ & $<0.01^{\mathrm{a}}$ \\
\hline Mean CCT $(\mu \mathrm{m})$ & $470.71 \pm 42.5$ & $457.64 \pm 29.04$ & $<0.01^{\mathrm{a}}$ & $450.19 \pm 32.7$ & $0.03^{\mathrm{a}}$ \\
\hline Mean Kmax (D) & $57.64 \pm 7.36$ & $58.72 \pm 7.13$ & $<0.01^{\mathrm{a}}$ & $60.31 \pm 7.96$ & $<0.01^{\mathrm{a}}$ \\
\hline \multicolumn{6}{|l|}{ Visual acuity } \\
\hline Median LogMAR & 0.2 & 0.3 & & 0.3 & \\
\hline Mean LogMAR & $0.16 \pm 0.19$ & $0.29 \pm 0.24$ & $<0.01^{\mathrm{a}}$ & $0.28 \pm 0.24$ & $0.01^{\mathrm{b}}$ \\
\hline Mean change in lines of Snellen VA & & $-0.79 \pm 0.89$ & $<0.01^{\mathrm{b}}$ & $-0.50 \pm 0.79$ & $0.01^{\mathrm{b}}$ \\
\hline
\end{tabular}

$S D$ standard deviation, $C X L$ collagen cross linking, $D$ dioptre, $C C T$ central corneal thickness, $B C V A$ best corrected visual acuity.

${ }^{a}$ Paired two-sided $t$-test.

${ }^{\mathrm{b}}$ One-sample $t$-test.

(median 2; mean 3.5; range 1-7). There were 117 appointments for the 34 patients that did not receive CXL in either eye during this study period.

\section{Discussion}

Early intervention with CXL at first presentation remains controversial, as the procedure carries the potential for complications that may result in reduction in vision. These include development of corneal stromal haze, microbial keratitis, scar formation, and failure of treatment resulting in continued ectasia progression [13, 14]. In our cohort, two eyes out of 56 (3.6\%) developed keratitis following CXL. However, these uncommon risks need to be balanced with the potential benefits of arresting progression and eventual avoidance of corneal transplantation. The average duration between initial presentation and CXL treatment was over 1 year in our cohort, and we also identified significant time delays between time of listing to delivery of treatment, which is a further source of unrecognised progression. Variability in, or unreliable, topographic readings can also delay detecting progressive disease, which increases the risk of 'silent' progression during monitoring and can influence the decision to treat $[13,15,16]$.

We found $41 \%$ of our eyes had documented progression over the 4-year period, comparable to a large Dutch study where 230 of their 504 monitored eyes $(46 \%)$ underwent CXL [17]. Young patients with keratoconus are likely to have unrecognised visual and topographic changes prior to initial ophthalmic referral. For this reason, previous publications have proposed CXL treatment at time of initial presentation for young patients with keratoconus $[5,18,19]$. Similar to the modern glaucoma management philosophy (treatment before damage), we agree that patients under 21 years of age with keratoconus should be offered CXL at initial presentation, rather than delaying treatment until evidence of disease progression. Applying this policy change to our young Glasgow cohort, the 56 eyes that underwent CXL could have avoided significant topographic deterioration or mean VA loss of 0.79 lines (median loss of 1 line). If all 56 eyes requiring CXL were treated at first presentation without monitoring for progression, 140 consultations would have been avoided in this cohort, with a conservative potential cost saving of $£ 18,900$ (clinic appointment cost £135; local NHSGGC estimate). However, this policy would have resulted in 28 potentially unnecessary CXL procedures (and exposure to the $3 \%$ risk of complications) if our whole cohort had their first/worse eye treated at presentation [13]. We have shown that young patients who progress have more extreme topography at presentation. More validated research is required to identify parameters at presentation to better identify those patients who are likely to experience progression and who require immediate CXL. Regardless of any change in treatment policy, the impact of stopping eye rubbing behaviour should not be underestimated and is a viable treatment option during any monitoring period [19-21]. Maximising clinical capacity has been a priority during the present COVID19 restrictions and will remain a challenge for the foreseeable future. In light of this, we propose that the financial costs, clinical capacity, and visual implications of requiring documentation of keratoconus progression prior to CXL should be revisited in the younger population.

Author contributions DL had original idea. AS and KB performed data collection, performed statistical analysis, and drafted article. DL and KR edited article and provided senior support.

\section{Compliance with ethical standards}

Conflict of interest The author declares no competing interests.

Publisher's note Springer Nature remains neutral with regard to jurisdictional claims in published maps and institutional affiliations. 


\section{References}

1. McAnena L, Doyle F, O'Keefe M. Cross-linking in children with keratoconus: a systematic review and meta-analysis. Acta Ophthalmol. 2017;95:229-39.

2. Eissa SA, Yassin A. Prospective, randomized contralateral eye study of accelerated and conventional corneal cross-linking in pediatric keratoconus. Int Ophthalmol. 2019;39:971-9.

3. Sarac O, Caglayan M, Uysal BS, Uzel AGT, Tanriverdi B, Cagil N. Accelerated versus standard corneal collagen cross-linking in pediatric keratoconus patients: 24 months follow-up results. Cont Lens Anterior Eye. 2018;41:442-7.

4. Olivo-Payne A, Abdala-Figuerola A, Hernandez-Bogantes E, Pedro-Aguilar L, Chan E, Godefrooij D. Optimal management of pediatric keratoconus: challenges and solutions. Clin Ophthalmol. 2019;13:1183-91.

5. Chatzis N, Hafezi F. Progression of keratoconus and efficacy of pediatric [corrected] corneal collagen cross-linking in children and adolescents. J Refract Surg. 2012;28:753-8. https://doi.org/10. 3928/1081597X-20121011-01. Erratum in: J Refract Surg. 2013 Jan;29:72. PMID: 23347367.

6. Leung VC, Pechlivanoglou P, Chew HF, Hatch W. Corneal collagen cross-linking in the management of keratoconus in Canada: a cost-effectiveness analysis. Ophthalmology. 2017;124:1108-19. https://doi.org/10.1016/j.ophtha.2017.03.019. Epub 2017 Apr 27. PMID: 28457614.

7. Godefrooij DA, Mangen MJ, Chan E, O'Brart DPS, Imhof SM, de Wit GA, et al. Cost-effectiveness analysis of corneal collagen crosslinking for progressive keratoconus. Ophthalmology. 2017;124:1485-95. https://doi.org/10.1016/j.ophtha.2017.04.011. Epub 2017 May 19. PMID: 28532974.

8. Toprak I, Yaylali V, Yildirim C. Visual, topographic, and pachymetric effects of pediatric corneal collagen cross-linking. J Pediatr Ophthalmol Strabismus. 2017;54:84-89. https://doi.org/10.3928/ 01913913-20160831-01. Epub 2016 Sep 27. PMID: 27668869.

9. Padmanabhan P, Rachapalle Reddi S, Rajagopal R, Natarajan R, Iyer $\mathrm{G}$, Srinivasan $\mathrm{B}$, et al. Corneal collagen cross-linking for keratoconus in pediatric patients-long-term results. Cornea. 2017;36:138-43. https://doi.org/10.1097/ICO.0000000000001102. PMID: 28060058.

10. Al Suhaibani AH, Al-Rajhi AA, Al-Motowa S, Wagoner MD. Inverse relationship between age and severity and sequelae of acute corneal hydrops associated with keratoconus. Br J Ophthalmol. 2007;91:984-5.
11. Legrottaglie EF, Balia L, Camesasca FI, Vallejo-Garcia JL, Fossati G, Vinciguerra R, et al. Management of an ophthalmology department during COVID-19 pandemic in Milan, Italy. Eur J Ophthalmol. 2020. https://doi.org/10.1177/1120672120960334. Epub ahead of print. PMID: 32962415; PMCID: PMC7511831.

12. Goh YW, Gokul A, Yadegarfar ME, Vellara H, Shew W, Patel D, et al. Prospective clinical study of keratoconus progression in patients awaiting corneal cross-linking. Cornea. 2020;39:1256-60. https://doi.org/10.1097/ICO.0000000000002376. PMID: 32482959.

13. Oliphant H, Zarei-Ghanavati M, Shalaby Bardan A, VasquezPerez A, O'Brart D, Liu C. Corneal collagen cross-linking in keratoconus: primum non nocere. Eye (Lond). 2018;32:4.

14. Koller T, Mrochen M, Seiler T. Complication and failure rates after corneal crosslinking. J Cataract Refract Surg. 2009;358: $1358-62$.

15. Kreps EO, Jimenez-Garcia M, Issarti I, Claerhout I, Koppen C, Rozema JJ. Repeatability of the pentacam HR in various grades of keratoconus. Am J Ophthalmol. 2020;219:154-62.

16. Belin MW, Villavicencio OF, Ambrósio RR Jr. Tomographic parameters for the detection of keratoconus: suggestions for screening and treatment parameters. Eye Contact Lens. 2014;40:326-30. https://doi.org/10.1097/ICL.0000000000000077.

17. Wisse RPL, Simons RWP, van der Vossen MJB, Muijzer MB, Soeters N, Nuijts RMMA, et al. Clinical evaluation and validation of the dutch crosslinking for keratoconus score. JAMA Ophthalmol. 2019;137:610-6. https://doi.org/10.1001/jamaophthalmol. 2019.0415. PMID: 30920597; PMCID: PMC6567860.

18. Godefrooij DA, Soeters N, Imhof SM, Wisse RP. Corneal crosslinking for pediatric keratoconus: long-term results. Cornea. 2016;35:954-8. https://doi.org/10.1097/ICO.0000000000000819. PMID: 27027921.

19. Gomes JA, Tan D, Rapuano CJ, Belin MW, Ambrósio R Jr, Guell JL, et al. Group of panelists for the global delphi panel of keratoconus and ectatic diseases. Global consensus on keratoconus and ectatic diseases. Cornea. 2015;34:359-69. https://doi.org/10. 1097/ICO.0000000000000408. PMID: 25738235.

20. McMonnies CW. Behaviour modification in the management of chronic habits of abnormal eye rubbing. Cont Lens Anterior Eye. 2009;32:55-63. https://doi.org/10.1016/j.clae.2008.11.001. Epub 2009 Feb 1. PMID: 19188087.

21. Moran S, Gomez L, Zuber K, Gatinel D. A case-control study of keratoconus risk factors. Cornea. 2020;39:697-701. https://doi. org/10.1097/ICO.0000000000002283. PMID: 32040008. 